(RESEARCH ARTICLE)

\title{
Innovative use of waste tyres: Noise-barriers and geoengineering
}

\author{
Theodor Haas ${ }^{1,}{ }^{*}$, Erich Markl ${ }^{2}$ and Maximilian Lackner ${ }^{2}$ \\ ${ }^{1}$ Mag. art. Theodor Haas, c/o Handel - technische Anlagen Annemaria Haas, Reinthalgasse 55, 4470 Enns, Austria. \\ ${ }^{2}$ University of Applied Sciences Technikum Wien, Höchstädtplatz 6, 1200 Vienna, Austria.
}

Publication history: Received on 10 November 2020; revised on 16 November 2020; accepted on 20 November 2020

Article DOI: https://doi.org/10.30574/wjaets.2020.1.1.0024

\begin{abstract}
Globally, more than 1 billion waste tyres are produced every year, and environmentally friendly end-of-life scenarios are highly sought after. Incineration to capture energy is a common practice. An improvement to sustainability is a cascaded use, where worn-out tyres are first being deployed in a meaningful way, e.g. as noise barriers or as embankment stabilization, where they can add value for several years to decades, before they are incinerated. The novel innovative use cases for tyres were found to offer advantages for the environment, while saving costs over materials that are being deployed today. This paper presents two recent innovations with waste tyres by a private inventor, and also highlights critical success factors for this type of innovator. Perseverance is one character trait a private inventor has to demonstrate in order to land a true innovation, focus a critical activity. Waste tyres can be considered an underutilized raw material.
\end{abstract}

Keywords: Innovation; Private Inventor; Upcycling; Waste Management; Sustainability; Invention

\section{Introduction}

Waste tyres are produced in huge quantities, on the order of 1 billion tons globally per year [1]. According to the RMA (Rubber Manufacturer's Association), in the United States alone, 230 million tons of waste tyres are generated every year. Production is estimated at 3 billion tyres per year [2]. In Europe the recovery rate of tyres is approx. up to 96\%, but only $18 \%$ are retreated and/or reused [1]. Waste tyres pose significant fire risks upon storage, and they bring about serious environmental health problems when stored or disposed of incorrectly. Tyres consist of metal, cord, carbon black, natural and synthetic rubber plus additives. Since rubber is an elastomer, it cannot be remolded like thermoplastics. Therefore, recycling is difficult. Rubber devulcanization [3] has been studied as a means of capturing the raw material for reuse. Commonly, waste tyres are landfilled or incinerated, e.g. in cement factories, which causes emissions, due to their carbonaceous nature and sulfur content. Use of waste tyres for artificial reef creation is an alternative application [4], [5]. A new approach is the pyrolysis of tyres to yield pyrolysis oil [6] as diesel replacement or carbon black [7] as pigment. Modified carbon black [8] has been studied as a higher-value product from waste tyres. Waste tyres can also be shredded or ground to a granulate [8], which can e.g. be added to asphalt [9] or concrete [10], [11]. Syngas and char production have also been studied [12]. Bacillus sp was found to degrade tyres [13]. For an overview of used tyre recycling, see Table 1.

\footnotetext{
* Corresponding author: Theodor Haas, haasundhaas@aon.at

Mag. art. Theodor Haas, c/o Handel - technische Anlagen Annemaria Haas, Reinthalgasse 55, 4470 Enns, Austria.

Copyright (C) 2020 Author(s) retain the copyright of this article. This article is published under the terms of the Creative Commons Attribution Liscense 4.0.
} 
Table 1 Recyling of used tyres. Source [4].

\begin{tabular}{|c|c|c|c|}
\hline Application & Approx. Quantity & Approx. Unit of Application & Format \\
\hline Sea embankment & 3000 car tires & $500 \mathrm{~m} \times 1.5 \mathrm{~m}$ high & Whole \\
\hline Sound barriers & 20,000 truck tires & $1 \mathrm{~km} \times 3 \mathrm{~m}$ high & Whole/cut \\
\hline Artificial reef & 30,000 car tires & $1 \mathrm{~km} \times 1 \mathrm{~m}$ high & Whole/bale \\
\hline Drainage culvert bed & 50,000 tires & $1 \mathrm{~km}$ long & Whole/cut/bale/shred \\
\hline Coastal stabilization & 2000 bales & $1.3 \mathrm{~m} \mathrm{high} \times 1 \mathrm{~km}$ & Bales \\
\hline Embankment & $1,000,000$ car tires & $330 \mathrm{~m} \times 3 \mathrm{~m}$ high & Shred (compacted) $)^{r}$ \\
\hline Backfill & $80-100$ car tires & $1 \mathrm{~m}^{3}$ & Shred (compacted) \\
\hline Bridge abutment fill & 100,000 tires & $1 \mathrm{~m}$ wide $\times 200 \mathrm{~mm}$ & Shred (compacted) $)^{r}$ \\
\hline Lightweight fill & $2700-3600 \mathrm{~km} \mathrm{~m}^{2}$ & Layer thickness $\pm 1-6 \mathrm{~m}$ & Shred (compacted) \\
\hline Tram rail beds & 50,000 tires & $1 \mathrm{~km}$ & Shred (compacted) $)^{2}$ \\
\hline Equestrian track & 15 tires & $10 \mathrm{~m}^{2}$ with $15 \mathrm{~mm}$ thick & Shred \\
\hline Thermal insulation & 300,000 tires & $0.3 \mathrm{~m}$ thick $\times 10 \mathrm{~m}$ wide & Chip/shred ${ }^{a}$ \\
\hline Drainage layer & 300,000 tires & $0.3 \mathrm{~m}$ thick $\times 10 \mathrm{~m}$ wide & Chip/shred" \\
\hline Road surface & 70,000 tires & $1 \mathrm{~km} 1$ lane road & Granulate \\
\hline Play surface (25 mil) & 1400 tires & $\sim 500 \mathrm{~m}^{2}$ & Granulate \\
\hline Asphalt rubber & 3500 tires & $1 \mathrm{~km} \times 12 \mathrm{~m} \times 0.05 \mathrm{~m}$ & Granulate \\
\hline Animal mattresses & 18 tires & Unit & Granulate \\
\hline Sound barriers & 20,000 tires & $1 \mathrm{~km} \times 3 \mathrm{~m}$ high & Granulate \\
\hline Running tracks & 2700 tires & $400 \mathrm{~m} \times 7 \mathrm{~m}$ & Granulate \\
\hline Infill for artificial turf & 12,200 tires & Normal field & Granulate \\
\hline Safety tiles & 4 tires & $1 \mathrm{~m} \times 1 \mathrm{~m} \times 0.04 \mathrm{~m}$ & Granulate \\
\hline Elastic layers & 3 tires & $1 \mathrm{~m} \times 1 \mathrm{~m} \times 003 \mathrm{~m}$ & Granulate \\
\hline Mats or sheets & 1 tires & $1 \mathrm{~m} \times 1 \mathrm{~m} \times 001 \mathrm{~m}$ & Granulate \\
\hline Solid wheels (carts) & approximately $1 \mathrm{t}$ of tires & about 900 units & Granulate/powder \\
\hline Antistatic shoe soles & 1 tire & 6 shoe soles (adult) & Powder \\
\hline Pigments & 112 tires & $30-50$ pigments & Powder \\
\hline
\end{tabular}

"Quantity of tires depends on producer's formula and specifications BRRC, BioSiafe, ETRA, D. Humplency, La Sapienzi.

There are strong variations between countries in end-of-life scenarios of tyres [14].

Recycling, or waste management, has different dimensions, see Fig. 1.

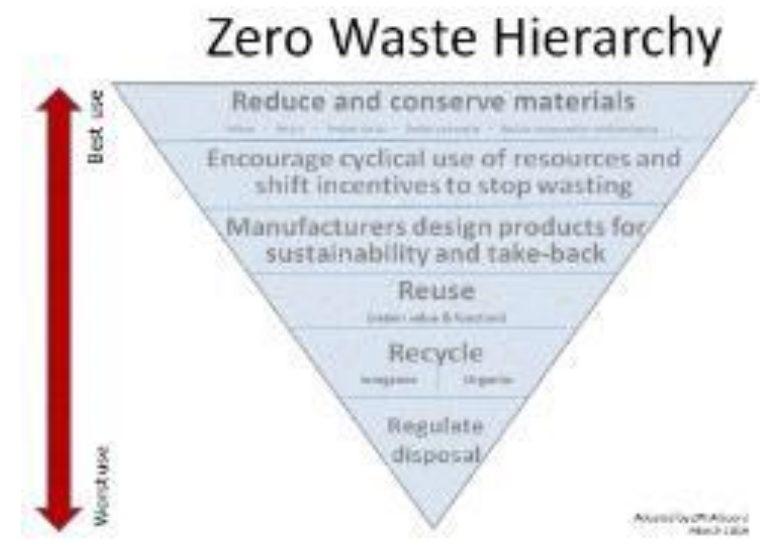

Figure 1 The waste pyramid. Source [15] 
As Fig. 1 shows, reuse of materials is to be preferred over recycling, which again is better than disposal. Applied to tyres, their reuse avoids the manufacturing of alternative products, e.g. in case of marine fenders, where old tyres serve as cost-effective bumpers. If tyres were not used, specially manufactured devices would have to be purchased. For sure, the target application needs to consider all relevant aspects such as leaching of additives, fire risk, mosquito breeding. Waste tyres are sometimes also used in private gardens for swings or to contain plants.

In this paper, two recent patents for industrial use of waste tyres are highlighted. They aim at a cost-effective, longlasting reuse of worn-out tyres with little processing effort: acoustic insulation walls and embankment stabilization.

\section{Innovative use of waste tyres I Acoustic insulation walls}

As Austrian private inventor, Theodor Haas has developed a noise-insulation board based on waste tyres. It has been filed as EP2824240 in 2015. The targeted application areas are not only highways, but also railroad tracks. For the former, an additional advantage is the softer surface in case of a crash, for the latter, lifetime is enhanced in case of flying debris (pepples). From the patent description: "A soundproofing wall is described with a support frame (1) and with car tires axially cut at one point, which are divided into equal sectors (7) connected by film hinges (8) by radial incisions (6) in the side walls and connected to the support frame (1) fastened sector strips (9) are pulled apart, the sector strips (9) lined up one behind the other in the longitudinal direction forming layers lying on top of one another. In order to create advantageous constructional conditions, it is proposed that the sectors (7) of the sector strips (9) of adjacent layers are offset from one another by half a sector length and that the supporting structure (1) extends over the layers continuously and in a grid spacing corresponding to half the sector length Has connecting anchors (5) which penetrate the sectors (7) of the sector strips (9) in the longitudinal center and support the film hinges (8) between the sectors (7) of the sector strips (9) on the outside facing away from the incisions (6)."

Fig. 2 shows key features of the invention:

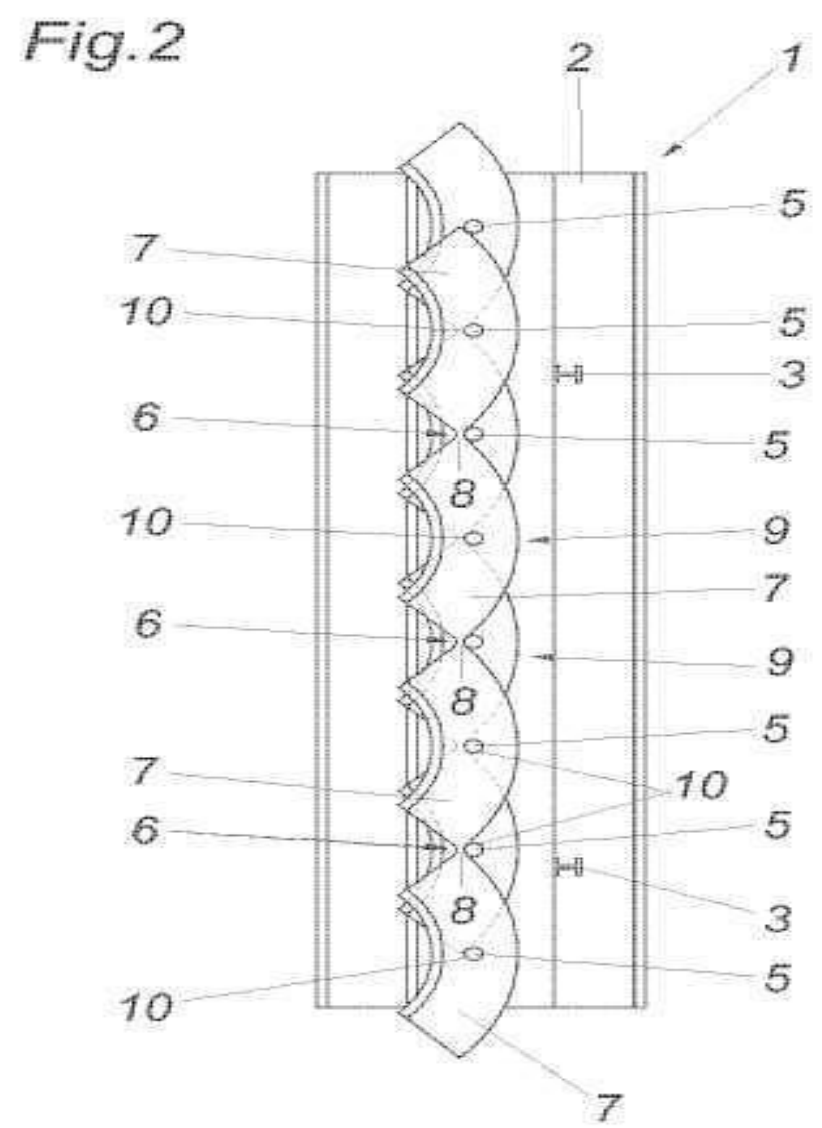

Figure 2 From the invention EP2824240, where waste tyres are processed into noise insulation boards. See text for details. 
The key feature of the novel acoustic insulation walls is the reused tyres; Standard car tyre of equal dimension are cut and fixed, so that noise in reflection and noise in transmission can be reduced, by up to $24 \mathrm{~dB}(\mathrm{~A})$ according to standardized measurements (ÖNORM 1793/2). The invention was tested by independent institutes and potential customers, see Fig. 3 for a test installation. It was found out that the installation is particularly suited for railways, since flying debris will not damage the panels. Also, for road usage, the invention offers advantages, in that an impact with that type of acoustic wall is less severe than with a standard road side, e.g. for less protected people like bikers. Longevity of the panels is achieved by the carbon black contained in the tyres, which protects the material from UV light. The back of the walls can be equipped with a fireproof board, so that flame spread can be controlled within a medium that is intrinsically combustible. The circular economy principle of "reuse" is well realized with this invention, which also recently took place in a competition for road noise abatement technologies [16].

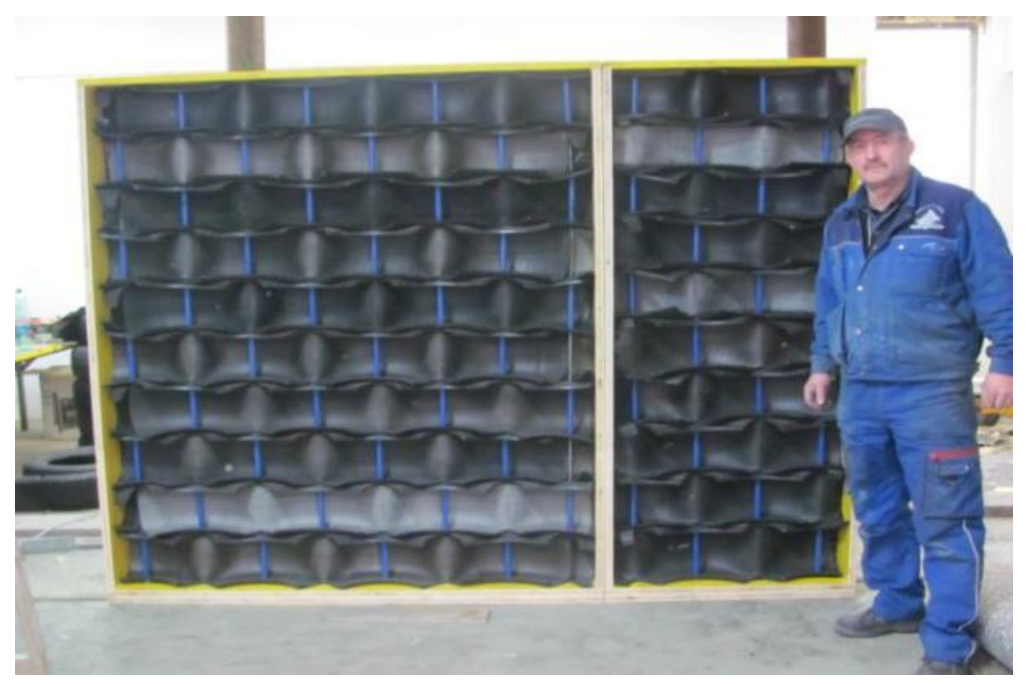

Figure 3 Test installation of EP2824240, approx. 3m long and 2m high.

Fig. 4 shows a mockup for a roadside installation, with colored design elements. The barrier fits well into the landscape.

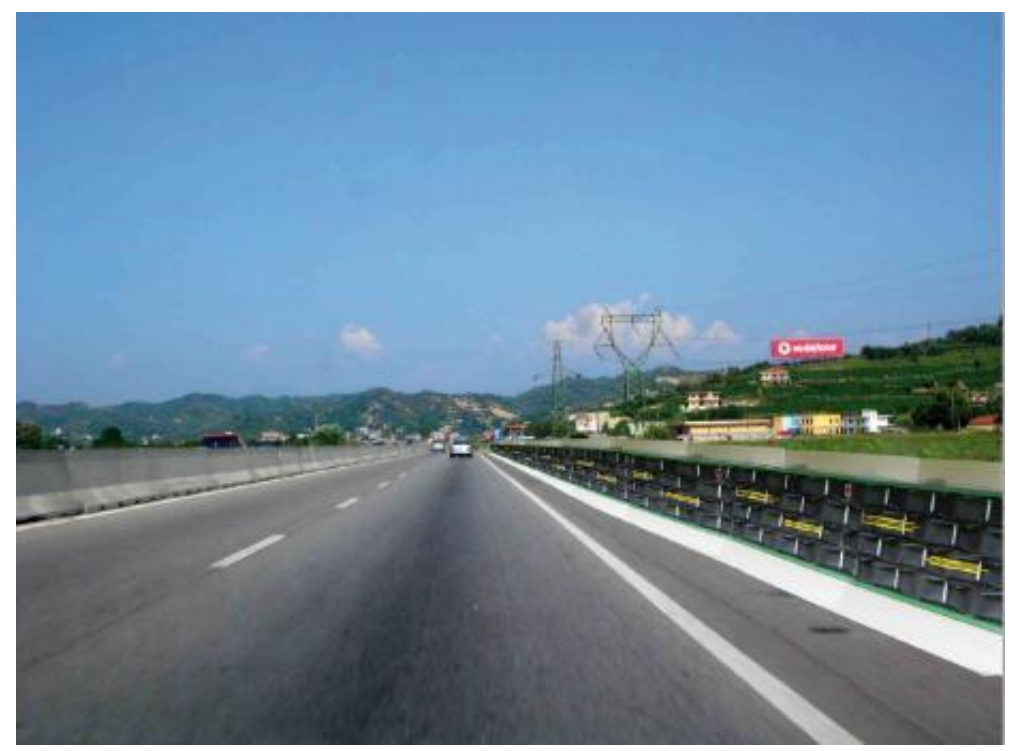

Figure 4 How the novel noise insulation barriers can look like in a practical installation.

Whereas air pollution has become less in cities due to improved flue gas cleaning and more environmentally friendly internal combustion engines on roads, the noise situation has not really gotten better, as Fig. 5 shows with an example of a large Swedish city. 


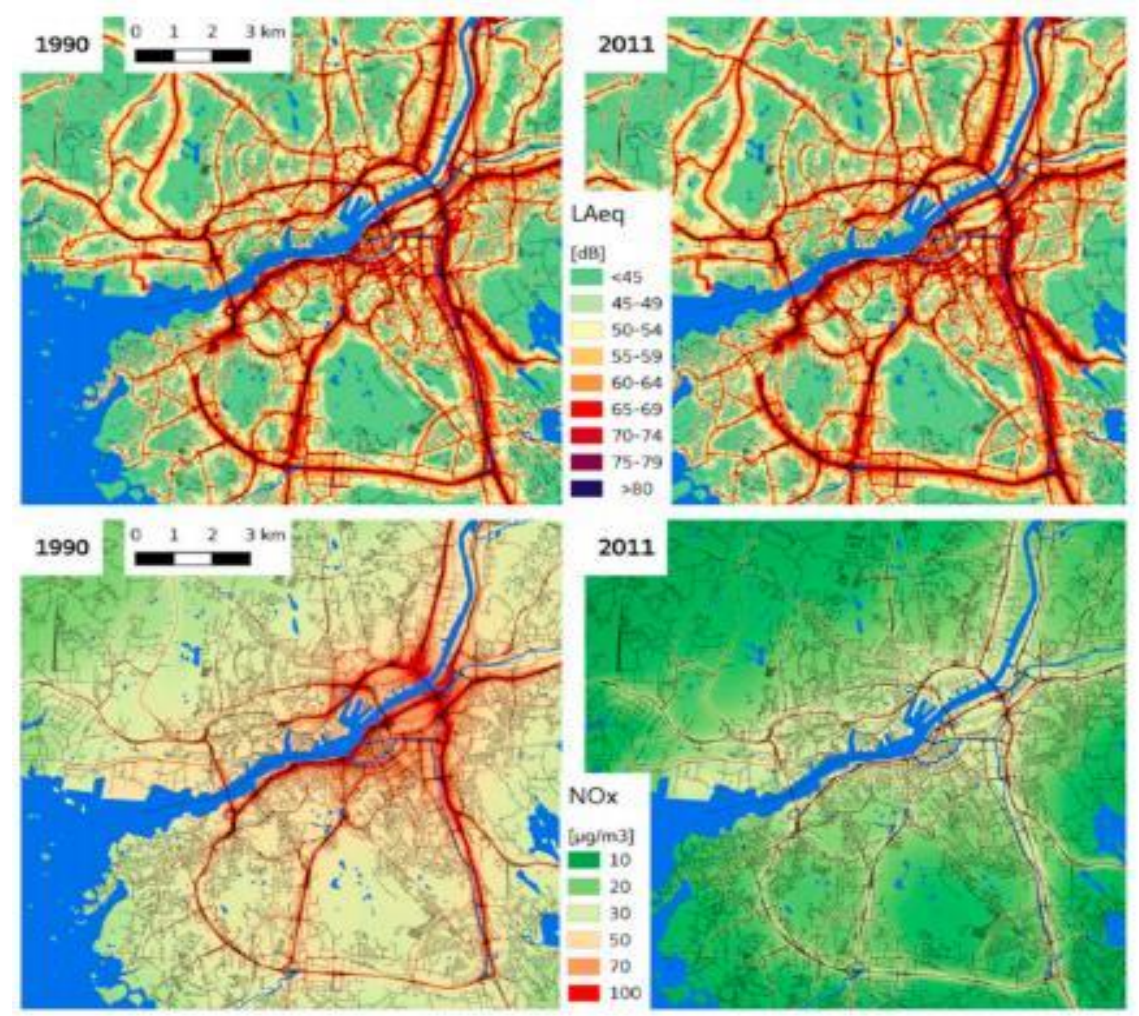

Figure 5 Top: Noise levels in Gothenburg, Sweden. Bottom: NOx levels in Gothenburg, Sweden. Whereas the NOx has strongly decreased from 1990 to 2011, the noise pollution has remained unchanged. Source: [17]

As one can see from Fig. 5, the air quality could be improved significantly over the 20 years under consideration here, whereas the noise pollution has not changed, apparently. There is still a large need to enhance noise reduction.

Waste tyres are already used for noise barriers today, as one of the large volume applications, mostly on firm of shredded material, compare Figs. 6 and 7.

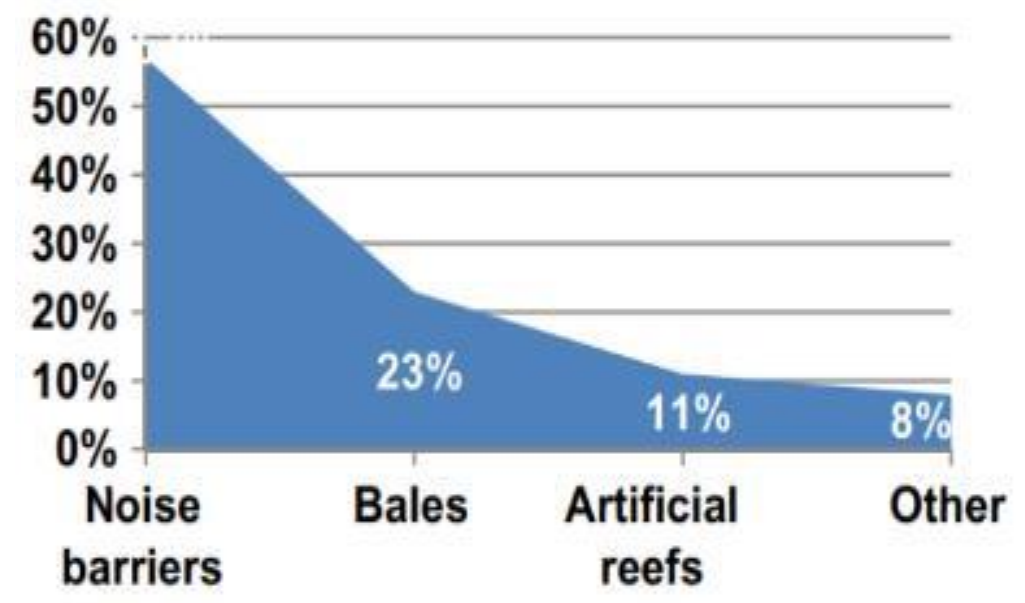

Figure 6 Some applications of waste tyres. Source: [4]

Noise barriers are a proper end-of-life outlet for tyres. Due to the high volume of waste tyres in all countries, many applications have been sought. 


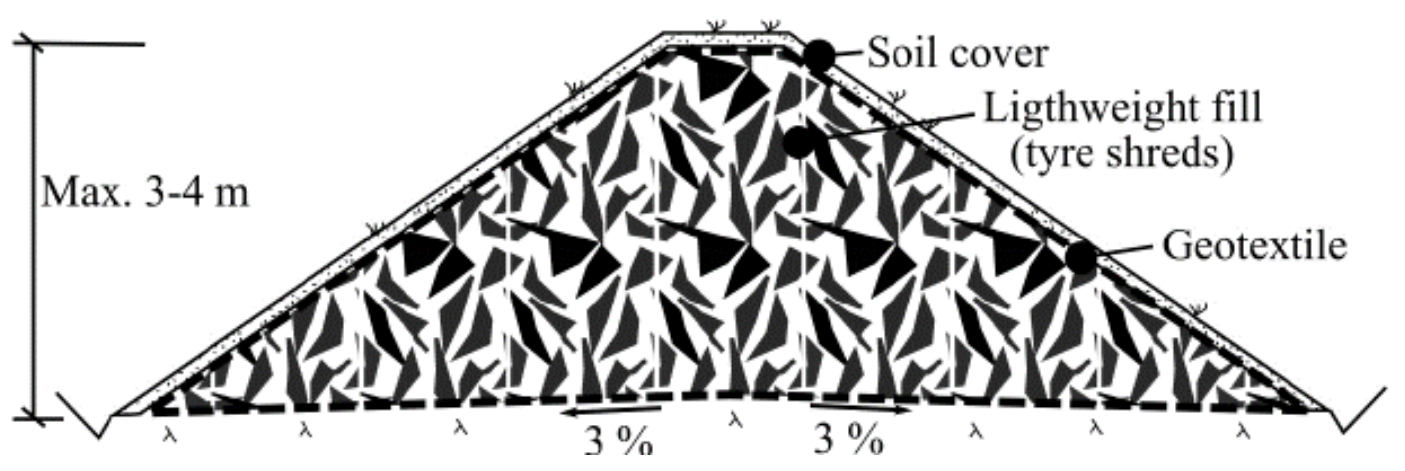

Figure 7 Example of lightweight fill of tyre shreds in a noise barrier. Source: [18]

The noise barrier in Fig. 7 uses shredded tyres that are covered by geotextiles and soil, to provide a cost-effective and long-lasting installation.

Already back in 1999, the Hong Kong Polytechnic University studied the application of recycled rubber components as noise barriers [19]. That project demonstrated that rubber tyre have a great potential to be further developed into a practical absorption material for reducing transportation noise. The EU-funded project "RUCONBAR" [20] has found that "46.4 $t$ of recycled rubber granules, obtained by recycling 7,800 waste car tyres, can be used for manufacturing 1 kilometre of noise barriers $3 \mathrm{~m}$ in height" [21]. A key finding was that a $31 \%$ reduction in greenhouse gas emissions compared to similar solutions available on the market was possible [21].

There are several types of noise barriers available on the market, from wood-based to concrete to transparent, for instance. People not only judge the noise reduction level, but also aesthetics of the solution. For an objective and subjective assessment of noise barriers, see e.g. [22]

With reference to Fig. 5, the exposure of the European population to traffic noise is still increasing, which is due to both urbanization and increasing traffic. As a significant part of noise pollution comes from the tyres, electromobility is no solution to avoid road noise. It is an established fact that health effects of noise are a large and growing area of concern for public health [17]. Road traffic is the main source of noise pollution [23]. There have been different approaches to noise cancellation [24], [25]. In one study [22], the response of a group of individuals has been investigated in relation to the reduction of perceived sound annoyance when traffic noise is attenuated by using a noise barrier. In general, female respondents were found to be more sensitive to noise [22].

It can hence be deducted that there is a large market for the invention, which in contrast to previously developed tyrebased solutions, works with entire pieces that are sliced and reconfigured. This will facilitate material separation at the end of life, which will be after an estimated 20-30 years. In contrast to composite materials, where e.g. rubber crumb is mixed into concrete, the tyre strips from the present invention can be separated from the rest of the construction and be given to the next cascaded use, e.g. pyrolysis to valuable raw materials.

\section{Innovative use of waste tyres II Embankment stabilization}

Austrian private inventor Theodor Haas has filed a second patent 4 years later, DE102019109235, 2019 (priority AT20180050334, 2018). In this invention, waste tyres are cut and fixed on a metal grid so that an element for embankment stabilization is obtained, see Fig. 8. 


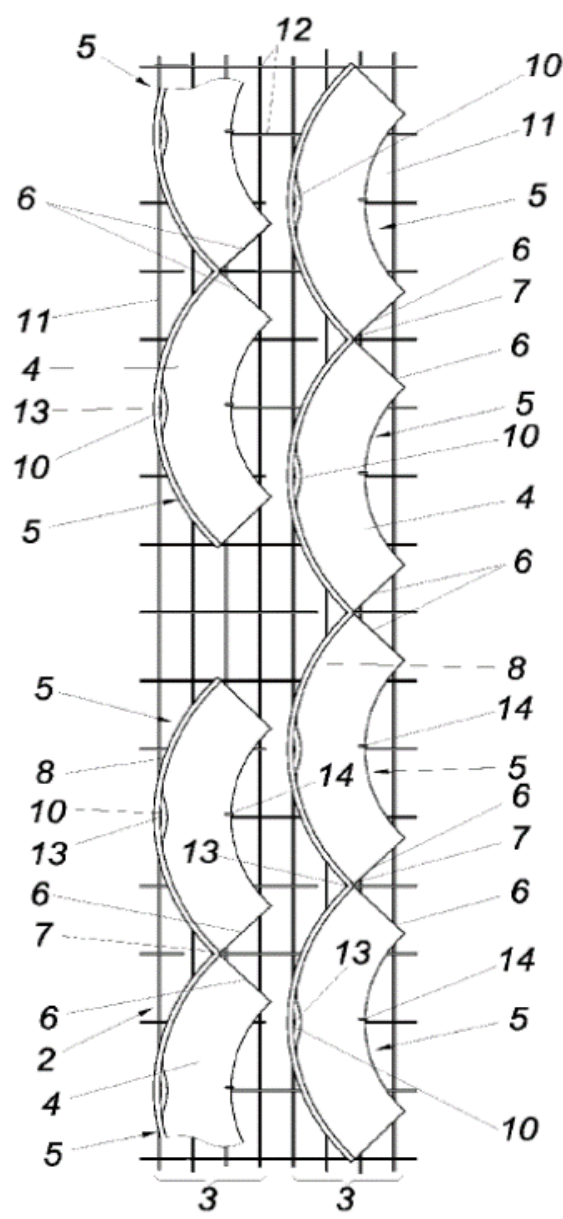

Figure 8 Embankment stabilization using waste tyres, according to DE102019109235.

The invention exploits the sturdy nature of tyres, where the steel and cord provide strength and stability and the rubber gives flexibility. The invention reads: "An embankment fastening is described with reinforcement made of car tires divided along a center plane normal to the axis, with the side walls (4) resting on a substrate (1) and covered with soil. In order to create advantageous construction conditions, it is proposed that the axially severed sector strips (3), which are divided by radial incisions in the side walls (4) into equal sectors (5) connected to one another by film hinges (7), are placed on a grid (2) form, which in the area of the film hinges (7) and in the central area of the sectors (5) from the grid surface bent up parts (13) of grid bars (12) extending transversely to the longitudinal direction of the sector strips (3) has that the sector strips (3) in the middle of the sectors (5) are provided with push-through openings (10) in the tread (9) so that the bentout parts (13) of the bars (12) on the one hand support the film hinges (7) and on the other hand the treads (9) in the pushthrough openings (10) and that the sector strips (3) in the middle of the sectors (5) in the area of the edge bead (15) of the side walls (4) with a longitudinal sector strip fen (3) extending bars (11) are connected".

Fig. 9 shows a prototype of this invention. 


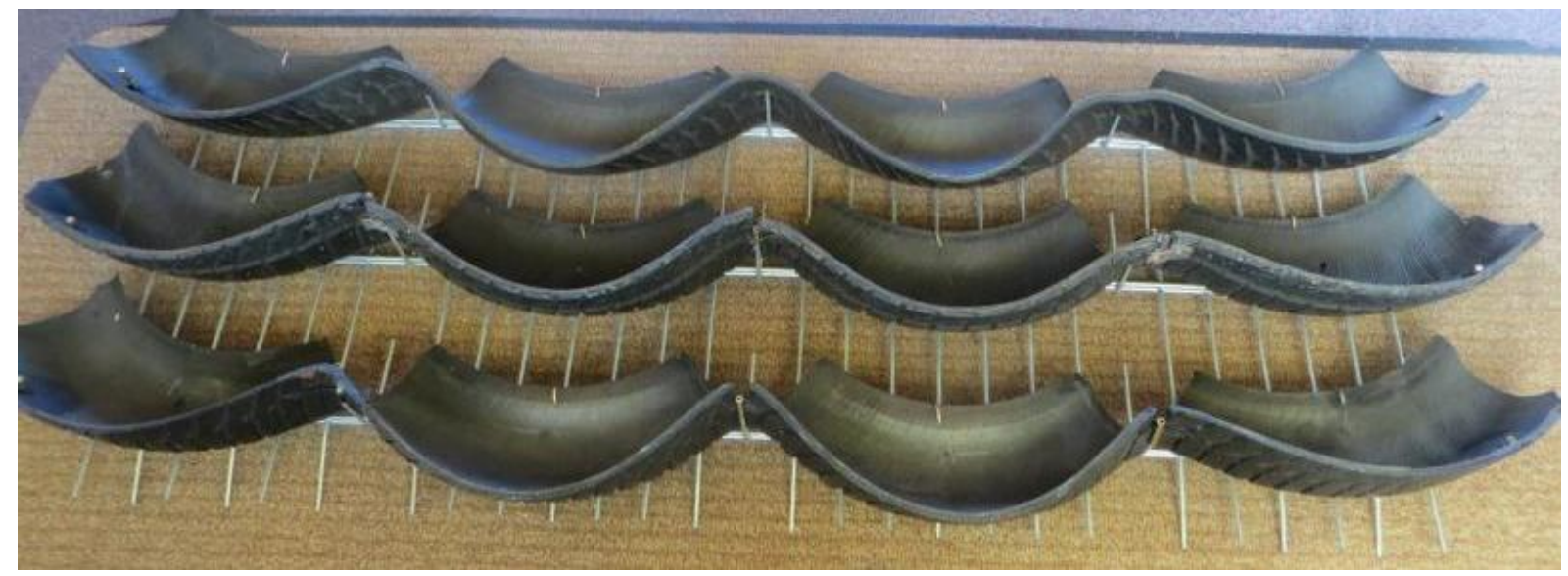

Figure 9 A 2.5m times 1m large prototype of DE102019109235 for use in embankment stabilization.

The idea to use waste tyres in geoengineering is not completely new. "Tyresoil" (Pneusol) was invented by Prof. Nguyen Thanh Long in 1978 [26] Already by 2004, there are more than 1000 installations worldwide [27], see also Fig. 10.
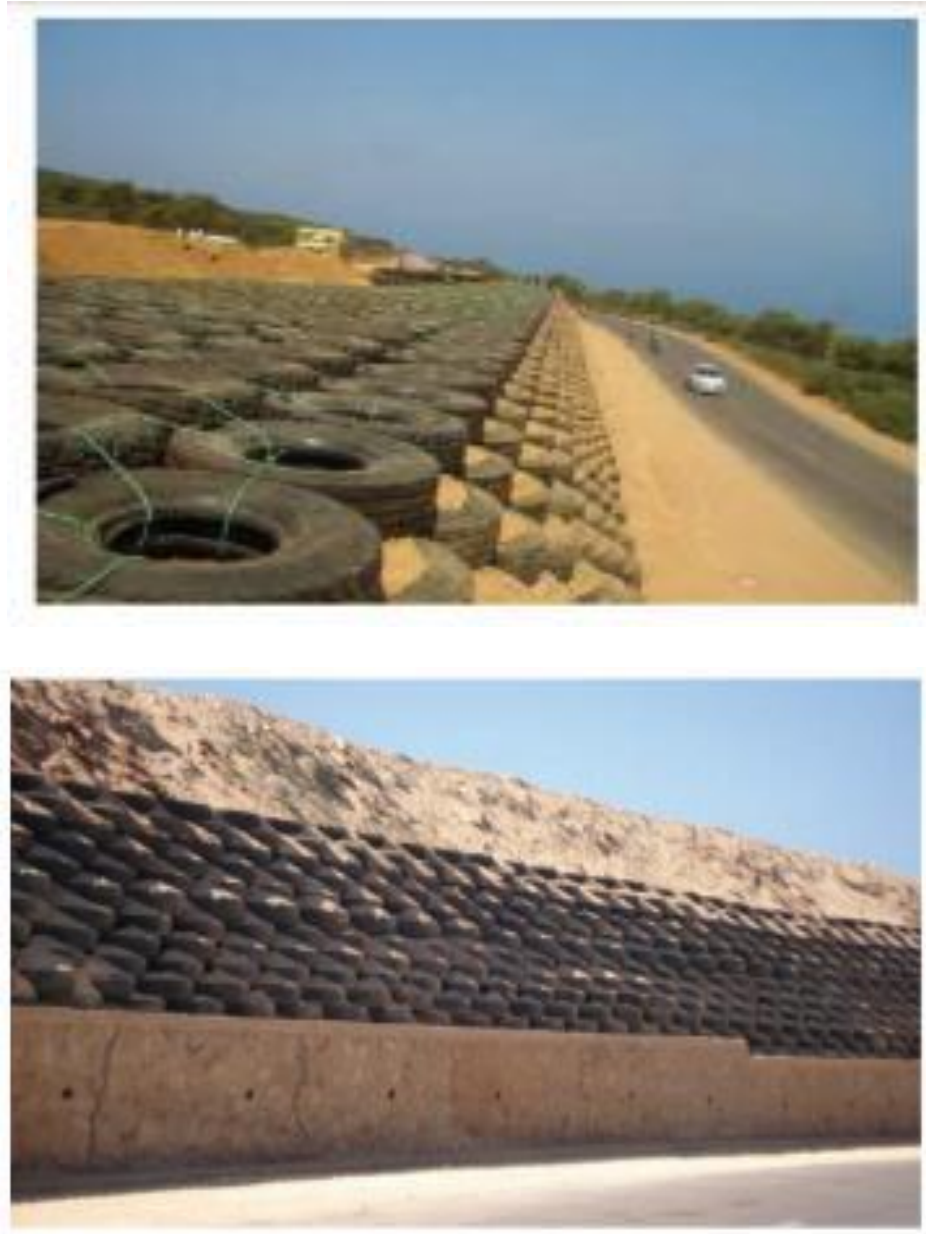

Figure 10 Use of entire worn-out tyres for roadside stabilization, here in Algeria [28].

The tyres are connected, using e.g. metal wire or ropes. Since the full tyres are deployed, there are some risks that water will be retained in them, giving rise to mosquito growth in some areas, or to instabilities of the constructions, hence the preparation of a hole is recommended, see Fig. 11. 


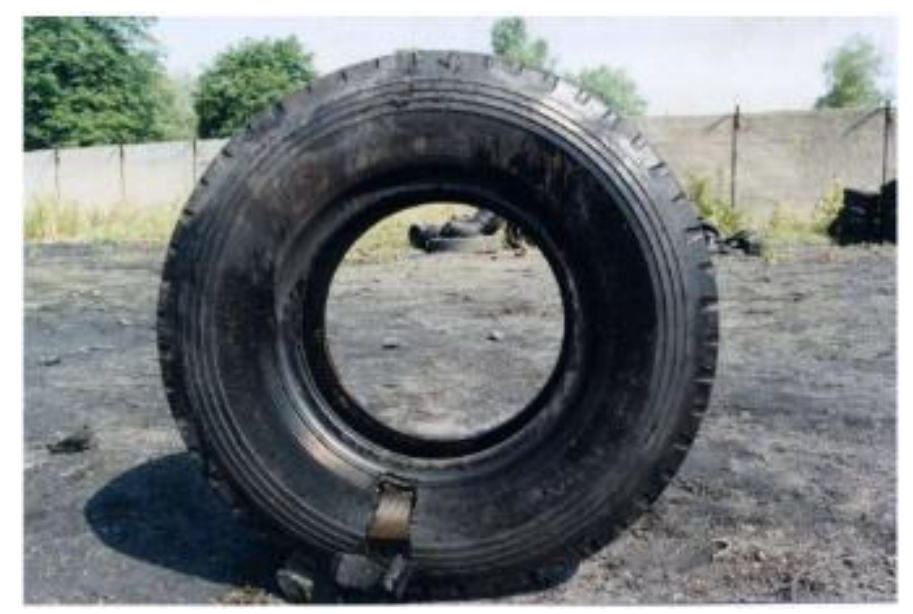

Figure 11 Opening in a full tyre to allow water run-off in an installation. Source: [29]

Tyres are long-lived and sturdy, hence they lend themselves well for use in slope stabilization projects. In many cases, landscaping works with steep slopes, which need to be stabilized, e.g. around bridges over traffic ways. Here, costeffective and durable solutions are needed, where tyres can add value.

An advantage of the novel solution DE102019109235 over the existing tyresoil projects is that material is used very efficiently, and a lower number of tyres is needed for a given surface area. The invention described above was tested for different such cases and found to be very effective in retaining soil and preventing massive erosion e.g. after heavy rainfall. The installation is typically covered with soil in its entity, so that after a few years, the vegetation has grown over the installation, yet it will remain effective in providing protection against earth slides. The elements, one of which is depicted in Fig. 9, can be produced in various sizes and shapes, and they can be connected to one another. Again, the invention fits well into the circular economy concept, in that a new utilization for scrap tyres other than disposal/incineration is found. The presented solution consumes less energy than if one had to make an embankment stabilization completely from new materials. If desired or needed, the stabilization can be excavated after its useful life; The tyre parts can easily be separated and subjected to a cascaded further use as mentioned above.

\section{Discussion of the $\mathbf{2}$ inventions on their way to an innovation}

Experience teaches that most inventions stay on paper, and that only a fraction is being put into practice and becomes a commercial success. The transition from an invention to an innovation has been discussed broadly in the literature, see e.g. [30]-[34]. in the case of the 2 inventions with waste tyres described above, the road has been a long and difficult one for the private inventor. Private inventors typically lack resources. They tend to invent in their spare time, with private savings, whereas corporations that have R\&D spendings based on current sales and cash flows are able to draw from multiple experts, who can dedicate substantial (working) time to further developing and improving an invention. Also, organizations have structures, processes and again resources for the next steps in commercialization, and they can benefit from various synergies. For a private inventor to become successful, there must be a strong drive, passion for one's ideas, and significant perseverance, so that others can be convinced of the own invention. The 2 inventions tackle a huge problem, namely the billions of waste tyres, but they do it in a different way than standard routes in operation today such as incineration: A step back on the waste pyramid is being made, from merely burning the material to capture heat, to truly reusing the materials - in novel ways. Out-of-the box thinking has sparked the ideas, and in discussions with several stakeholders, amongst them research organizations, test institutes and potential customers, these ideas were reformulated to become more specific and fit-for-practice. Being open as an inventor, listening the market needs, is a vital aspect. A private innovator needs to focus his or her efforts so that his or her resources are used with maximum effect.

\section{The role of the private inventor and critical success factors}

The example of Theodor Haas and his 2 inventions shows that a private person, after several years of studying possible uses for waste tyres, has come up with two different innovative applications. These were patented. The inventions were further developed with support from 2 universities, using private funds leveraged by public research grants. Also, experts from different fields were consulted. The inventor described the involvement of a patent attorney as critical for proper claim formulation. The 2 universities have helped the inventor to make a proof-of-concept and to gain credibility 
in product presentations and in different competitions. Valuable advice in the process was also provided by an inventors' organization, in this case the OPEV, the Austrian patent owners' and inventors' association [16]. Apart from a certain amount of monetary funds, the inventor needs a positive, affirmative environment, in order to cope with setbacks. It is not simple to find a buyer, licensee or partner, and a private innovator essentially has to handle all aspects of commercialization him-or herself. Strategies of private inventors on how to interest others in their products vary. One option is the attendance of an inventors' fair, such as the IENA [35], which in 2020 took place already for the 72 ${ }^{\text {nd }}$ time. Fig. 12 shows Theodor Haas with his booth at the fair and the prize that he has won there.
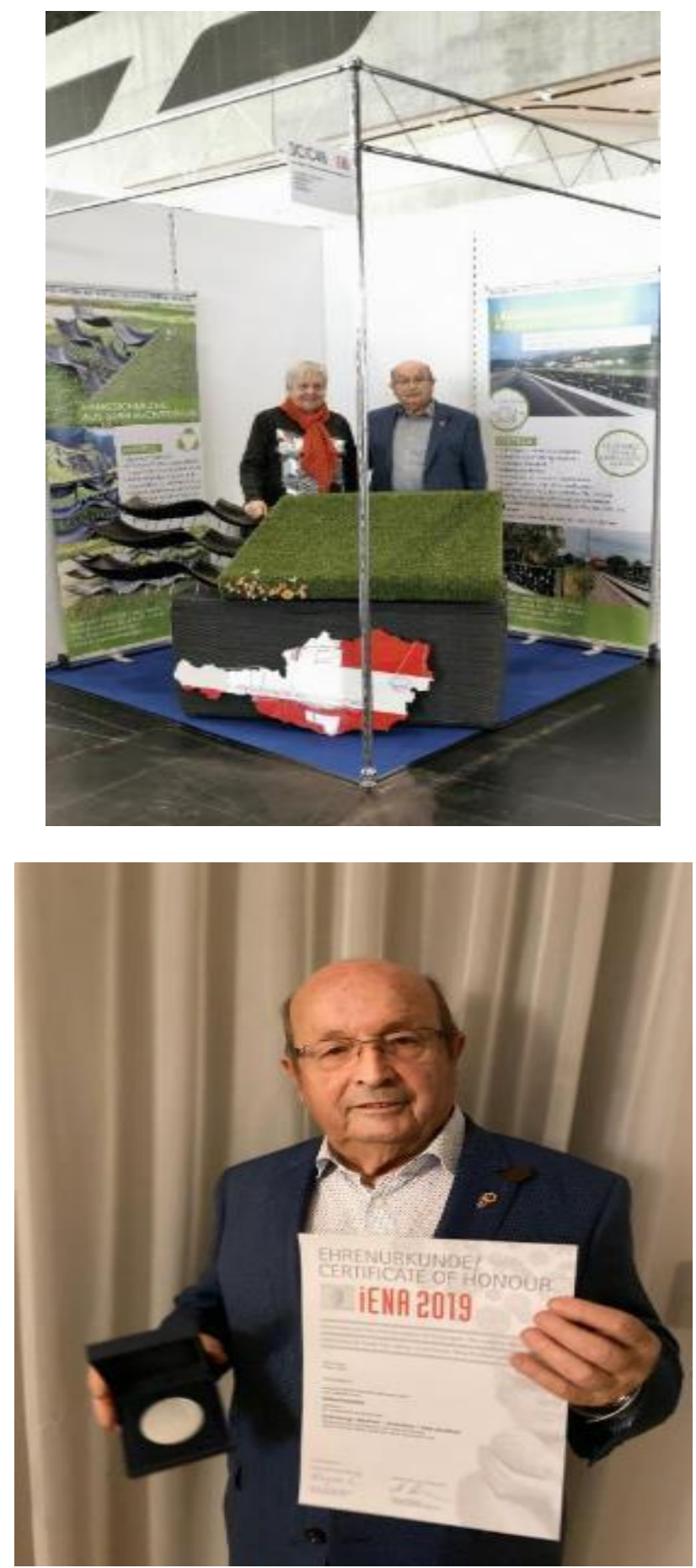

Figure 12 Top: Exhibition booth featuring the 2 waste-tyre-based inventions "noise barriers" and "slope stabilization", with the inventor in the background, at the IENA 2019. Bottom: Silver medal and certificate of recognition for the inventor eared at the fair. 
An inventors' fair is an opportunity for private inventors to meet possible customers, and to get feedback on their ideas and developments. No invention sells itself alone; Inventors need to get out to find potential partners as soon as patent filing has been completed, so that within the relatively short time before a decision to file further national applications is over, they secure interest from the market before committing (more) substantial funds. Patent marketing is crucial, and inventors need to budget for this, too, an not overlook its necessity [36].

\section{Conclusions}

More often than none, it is the simple ideas and concepts that lead to success in the marketplace. The 2 innovations discussed in this paper are not truly "rocket science", but they contribute to solving 2 major issues of these days: Global warming and resource depletion, in that waste (the tyres) is processed to novel applications, ones for that otherwise new resources would have been consumed.

The 2 applications highlight that waste does not always have to be incinerated. A cascaded use, where the worn-out tires are given a $2^{\text {nd }}$, meaningful use before final "thermal recycling", is definitely worth an effort. Private inventors tend to have limited resources, so they need to focus their efforts and show endurance in pursuing their ideas. Inventing alone is not enough, they need to have the market needs in mind and as early as possible, after securing their intellectual property rights by patenting, get out to find potential customers. A working prototype, or better reference installations, give credibility and increase the chances of success [37]. When a private inventor has a great idea, addresses an unsolved problem in the marketplace and has realistic views on how to commercialize and exploit the invention, chances are good that the invention becomes a true innovation.

\section{Compliance with ethical standards}

\section{Disclosure of conflict of interest}

The authors declare that there is no conflict of interest.

\section{References}

[1] Lulu Liu, Guojun Cai, Jun Zhang, Kai Liu, Evaluation of engineering properties and environmental effect of recycled waste tire-sand/soil in geotechnical engineering: A compressive review, Renewable and Sustainable Energy Reviews, July 2020

[2] https://www.freedoniagroup.com/industry-study/world-tires-3357.htm, accessed Nov. 2, 2020.

[3] Erich Markl and Maximilian Lackner, Devulcanization Technologies for Recycling of, Tire-Derived Rubber: A Review, Materials 2020; 13:1246; doi:10.3390/ma13051246

[4] Valerie L. Shulman, Tire Recycling, in: Waste (Second Edition)2019; Pages 489-515

[5] Christine Risso-de Faverney, Marielle E. Guibbolini-Sabatier, Patrice Francour, An ecotoxicological approach with transplanted mussels (Mytilus galloprovincialis) for assessing the impact of tyre reefs immersed along the NW Mediterranean Sea, Marine Environmental ResearchJuly 2010Volume 70, Issue 1:Pages 87-94

[6] T. Suchocki, L. Witanowski, P. Lampart, B. Gawron, Experimental investigation of performance and emission characteristics of a miniature gas turbine supplied by blends of kerosene and waste tyre pyrolysis oil, Energy, In press, journal pre-proof, Available online 22 October 2020; Article 119125

[7] Xiaolong Tian, Qianxiao Zhuang, Shuang Han, Huiguang Bian, A novel approach of reapplication of carbon black recovered from waste tyre pyrolysis to rubber composites, Journal of Cleaner Production, 20 January 2021

[8] Junqing $\mathrm{Xu}$, Jiaxue $\mathrm{Yu}$, Jianglin $\mathrm{Xu}$, Guangming Li, High-value utilization of waste tires: A review with focus on modified carbon black from pyrolysis, Science of The Total Environment, 10 November 2020

[9] Edoardo Bocci, Emiliano Prosperi, Recycling of reclaimed fibers from end-of-life tires in hot mix asphalt, Journal of Traffic and Transportation Engineering, October 2020; Volume 7, Issue 5:Pages 678-687

[10] Khuram Rashid, Ardavan Yazdanbakhsh, Munib Ul Rehman, Sustainable selection of the concrete incorporating recycled tire aggregate to be used as medium to low strength material, Journal of Cleaner Production1 July 2019; Volume 224:Pages 396-410 
[11] Zeno Ghizdăveț, Bianca-Maria Ștefan, Mihai Bratu, Sound absorbing materials made by embedding crumb rubber waste in a concrete matrix, Construction and Building Materials, 15 October 2016; Volume 124:Pages 755-763

[12] Zhiwei Wang Kiranraj, G. Burra Mengju Zhang, Ashwani K. Gupta, Co-pyrolysis of waste tire and pine bark for syngas and char production, Fuel 15 August 2020

[13] Weng Chon Lao, Renata Alves de Toledo, Hojae Shim, Degradation of scrap tyre by Bacillus sp. - Kinetic aspects of major environmental parameters and identification of potential growth substrates, International Biodeterioration \& BiodegradationFebruary 2019; Volume 137:Pages 95-101

[14] Vincenzo Torretta, Elena Cristina Rada, Lucian Ionel Cioca, Treatment and disposal of tyres: Two EU approaches. A review, Waste Management, November 2015; Volume 45:Pages 152-160

[15] Zero Waste Europe, https://zerowasteeurope.eu/2013/04/zero-waste-hierarchy/, accessed Nov. 2, 2020.

[16] OPEV, http://www.opev.at, accessed Nov. 2, 2020.

[17] Eva M. Andersson, Mikael Ögren, Leo Stockfelt, Road traffic noise, air pollution and cardiovascular events in a Swedish cohort, Environmental ResearchJune 2020; Volume 185:Article 109446

[18] Tommy Edeskär, Use of Tyre Shreds in Civil Engineering Applications, Luleå University of Technology, Doctoral Thesis, https://www.diva-portal.org/smash/get/diva2:989894/FULLTEXT01.pdf, accessed Nov. 2, 2020.

[19] The Hong Kong Polytechnic University, The application of recycled rubber components as noise barriers, https://www.ecf.gov.hk/text/en/archives/9902.html, accessed Nov. 2, 2020.

[20] Ruconbar,http://www.ruconbar.com/rcnb/wp-content/uploads/2013/02/RUCONBAR_CETRA_2012.pdf, accessed Nov. 2, 2020.

[21] Ecoinnovative, http://ecoinnovative.eu/ruconbar-rubeberised-concrete-noise-barriers/, accessed Nov. 2 , 2020.

[22] J. RedondoM. P. Peiró-TorresP. Amado-Mendes, Correlation between objective and subjective assessment of noise barriers, Applied Acoustics15 January 2021; Volume 172:Article 107640

[23] David Montes González, Juan Miguel Barrigón Morillas, Luís Godinho, Evaluation of exposure to road traffic noise: Effects of microphone height and urban configuration, Environmental Research, December 2020

[24] A.K.M Fazlul Haque, A.A.M Muzahid, S. I. M. M. Raton Mondol and Md. Zahirul Islam, Acoustic Echo Cancellation for the Advancement in Telecommunication, IJAITI (International Journal of Advance Innovations, Thoughts \& Ideas) 2013; 2:135

[25] Ramanpreet Kaur, Simarpreet Kaur, Noise Cancellation Using Fuzzy Inference System, IJAITI (International Journal of Advance Innovations, Thoughts \& Ideas) 2012; 1:112

[26] http://www.caribriskcluster.org/wp-content/uploads/2015/05/Formation-Pneusol-ENG.pdf, accessed Nov. 2, 2020.

[27] Pneusol, https://pneusol.eu.org/index.en.html, accessed Nov. 2, 2020.

[28] F. Belabdelouhab, N. Kebaïli, Large scale experimentation Slope stability of «Soil Tyre» in Mostaganem (Algeria), International Conference on Technologies and Materials for Renewable Energy, Environment and Sustainability, TMREES15

[29] Pneusol, https://pneusol.eu.org/TheseLong/FR/8-ANNEXE.Pneusol.pdf, accessed Nov. 2, 2020.

[30] Luiz Stephany Filho, Elda Fontinele Tahim, Vitória Maria Serafim, Cynara Barros de Moraes, From invention to Innovation-challenges and opportunities: a multiple case study of independent inventors in Brazil and Peru, RAI Revista de Administração e Inovação, July-September 2017; Volume 14 Issue 3:Pages 180-187, First available on 27 May 2017

[31] Susan K. Cohen, Turanay Caner, Converting inventions into breakthrough innovations: The role of exploitation and alliance network knowledge heterogeneity, Journal of Engineering and Technology Management, April-June 2016

[32] Manfred Schmiemann, The link between R\&D, inventions and innovations in Europe, World Patent Information, March 1999; Volume 21 Issue 1:Pages 43-45

[33] Mark J. Ahn, Ofer Zwikael, Rebecca Bednarek, Technological invention to product innovation: A project management approach, International Journal of Project Management, August 2010; Volume 28 Issue 6:Pages 559568, First available on 1 December 2009 
[34] Heinz-Dieter Haustein, Erich Neuwirth, Long waves in world industrial production, energy consumption, innovations, inventions, and patents and their identification by spectral analysis, Technological Forecasting and Social Change, September 1982; Volume 22 Issue 1:Pages 53-89

[35] IENA, https://www.iena.de/en/visitors/success-story-of-iena/, accessed Nov. 2, 2020.

[36] Roman Harrer, Maximilian Lackner, Integrated Marketing Communications (IMC) in the commercialization of intellectual property (IP), Int. J. Intellectual Property Management, 7 (1/2), 47-56 (2014).

[37] Andrew O. Martyniuk, Ravi K. Jain , Harry J. Stone, Critical success factors and barriers to technology transfer: case studies and implications, International Journal of Technology Transfer and Commercialisation 2(3), 2003. 